IV. LOS PROCESOS ELECTORALES EN AMÉRICA CENTRAL (I)

(Año 1989)

\author{
CAYETANO NÚÑEZ RIVERO * \\ Profesor Titular de Derecho Político \\ UNED
}

* El profesor Núñez Rivero ha asistido como observador internacional a los diversos procesos electorales habidos en América Central. 


\section{SUMARIO}

1. El SALVADor.-1. Datos generales. 2. El marco social y económico. 3. El sistema electoral. 4. Fuerzas políticas concurrentes. 5. Resultados electorales.

II. PANAMÁ.-1. Datos generales. 2. El marco social y económico. 3. El sistema electoral. 4. Fuerzas políticas concurrentes. 5. Resultados electorales. 
Revista de Derecho Político, núm. 32, 1991, pp. 397-424

\title{
IV. LOS PROCESOS ELECTORALES EN AMÉRICA CENTRAL (I) (Año 1989)
}

\author{
POR \\ CAYETANO NÚÑEZ RIVERO \\ Profesor Titular de Derecho Político
}

UNED

\section{EL SALVADOR}

\section{DATOS GENERALES}

La República de El Salvador es el Estado centroamericano de menor extensión - $21.000 \mathrm{~km}^{2}$ - aunque uno de los más poblados, contando con algo más de 5.000 .000 de habitantes, de tal forma que tiene una densidad demográfica de $245 \mathrm{~h} . / \mathrm{km}^{2}$, lo que le convierte en el pais más densamente poblado de Iberoamérica. La incorporación de este territorio a la Corona de Castilla se produjo en 1524, y durante la época colonial fue dependiente fundamentalmente de la Capitania General de Guatemala, separándose del Imperio español en 1821, cuando lo hace esta Capitanía General con anterioridad, a este territorio le correspondió un diputado a Cortes en Cádiz - el presbitero José María Delgado- que tras ser elegido no pudo asistir a las Constituyentes de 1812.

Después de ser dependiente de México y de la Federación Centroamerica en 1841, se creo la República de El Salvador, dentro de la República Federal de Centroamérica, y en 1859 se constituyó en República independiente, aunque de hecho ya funcionaba como tal desde 1841.

La vida política de la República de El Salvador se ha caracterizado por la inestabilidad que se deriva de problemas fronterizos con Guatemala y Honduras, así como de una total dependencia del mercado mundial en cuanto al café y algodón se refiere, lo que ha posibilitado la existencia de una oligarquía agraria poderosa y amparada en el ejército, y la existencia 
de amplias capas sociales marginadas, en las que sectores de la misma, especialmente tras el fracaso de la experiencia renovadora y democrática, 1950-60, han buscado soluciones extrasistema, de tal forma que desde esa fecha el país ha estado sujeto a una dinámica de guerra civil entre una guerrilla poderosa y un ejército monolítico que actuaba imponiendo sus criterios en la política nacional.

\section{Los últimos años}

Tras la dinámica de los años setenta caracterizada por el incremento de la actividad guerrillera, por una parte, y de la represión gubernamental, por otra, en 1979 se constituye una Junta cívico-militar que después de derrocar al Presidente, general Carlos Humberto Romero, inicia la transición política que llevará en 1980 a la Presidencia al demócrata-cristiano Napoleón Duarte, el cual gobernará en un primer período, 1980-82, sucediéndole Álvaro Magaña; durante este tiempo, una Asamblea legislativa (elegida en marzo de 1982), compuesta por 60 miembros de mayoria relativa democristiana, elaborará un nuevo texto constitucional que está vigente desde diciembre de 1983.

En mayo de 1984, después de celebrarse la segunda vuelta de las elecciones, ya que en la primera (marzo del mismo año) ninguna fuerza obtuvo la mayoría absoluta, es nuevamente elegido Presidente, con el 54,59 por 100 de votos válidos, Napoleón Duarte. La Alianza Repúblicana Nacionalista (ARENA), de carácter derechista, obtuvo el 46,40 por 100 , configurándose como la segunda fuerza política del país.

El Presidente electo acabaría su mandato presidencial, y así, según el artículo 154 del texto constitucional, las siguientes elecciones serian convocadas para el 19 de marzo de 1989.

\section{EL MARCO SOCIAL Y ECONÓMICO}

No obstante el indudable triunfo que supuso en un proceso de transición política y consolidación democrático el finalizar el mandato presidencial, otros factores se nos van a revelar como altamente negativos en este proceso: podemos sintetizar los mismos en los siguientes puntos:

- Crisis económica.

- El fracaso de integración de la guerrilla al sistema político.

- La situación geopolítica del país. 
La crisis económica que afecta a El Salvador viene derivada de varios aspectos, entre los que se destaca la caída en el mercado mundial de los precios de algodón, café y otros, lo que unido a la inseguridad existente en amplias zonas del territorio ha traído consigo una disminución importante de la producción.

La concentración de los sectores productivos en manos de una reducido grupo de propietarios ha posibilitado que los ataques del FMLN hayan sido especialmente eficaces, en cuanto a paralizar la produción y a destruir ampliamente la infraestructura económica del pais mediante la ocupación de haciendas, destrucción de industrias, etc., de tal forma que sólo sobrevive en ocasiones una producción destinada al autoabastecimiento. Debido a esto, la deuda externa, tanto la privada como la pública, ha aumentado considerablemente, contribuyendo a un progresivo deterioro económico. Por último, la inseguridad en el transporte imposibilita el desarrollo real de un auténtico mercado nacional.

El fracaso de integración de la guerrilla en el sistema político salvadoreño implica que el país sigue inmerso en una cruenta guerra civil y, como indica Segundo MONTES, los procesos electorales se dan en una situación de profunda -orgánica-crisis nacional, de enfrentamiento entre dos proyectos diametralmente opuestos. En semejantes circunstancias, las elecciones promovidas y realizadas por una de las partes en conflicto, bajo el auspicio de las fuerzas internas y externas que la respaldan, adquieren una dimensión predominantemente ideológico-política como medida contrainsurgente: una gran cantidad de votos, asi como la impresión de concurrencia masiva y aglomeración en los lugares concentrados de votación, se utilizarán como argumento para desligitimar a la guerrilla e intentar demostrar la carencia de base social. Un tal proceso eleccionario a lo más que podrá aspirar es a ser el instrumento para una democracia formal, pero ni resolverá los verdaderos problemas del país, ni mucho menos será capaz de alcanzar la democracia real (S. MONTES, 1985).

Es en este contexto en el que el FMLN (Frente Farabundo Martí para la Liberación Nacional) no acepta el proceso de transición hacía una democracia de corte clásico y plantea una guerra total con el objeto de implantar otro sistema, en el que, por otra parte, precisamente los encargados de sostener en armas el mismo no están acostumbrados a vivir en un sistema democrático habiendo mostrado sus preferencias políticas en el pasado por otro tipo de régimen, en esta situación, se produce el proceso electoral de marzo de 1989, que de esta forma sólo ha sido sostenido por un sector de la población representado por algunas fuerzas políticas.

Otros factores que indudablemente arrojan elementos de inestabilidad al sistema se derivan de la ubicación geogrática del país, limitando con Guatemala, que se encuentra a su vez inmersa en un difícil proceso de consolidación democrática con elementos golpistas que quieren volver a situaciones anteriores y una guerrilla activa, así como con Honduras, que 
debe afrontar la existencia de miles de refugiados nicaragüenses y de campamentos de las fuerzas antisandinistas que, en muchos casos, no reconocen otra autoridad que ellas mismas; Nicaragua, inmersa en una difícil guerra civil, y aunque algo más apartada, Panamá, que sufre una grave crisis institucional por resolver. Indudablemente en este contexto, salvo el caso costarricense, es difícil consolidar un proceso democrático institucional.

\section{EL SISTEMA ELECTORAL}

\section{El cuerpo electoral}

Según el artículo 76 de la Constitución de diciembre de 1983, el cuerpo electoral está formado por todos los ciudadanos capaces de emitir voto, aunque para el ejercicio del sufragio es condición indispensable, según el artículo 17, el estar inscrito en el Registro electoral, que es elaborado por el Consejo Central de Elecciones y funciona de forma autónoma a cualquier otro registro público.

Por otra parte, para poder ejercitar el derecho al voto es condición indispensable estar provisto del carnet electoral. En la práctica para las últimas elecciones habidas, de un cuerpo electoral posible de 2.512 .802 personas, sólo contaban con carnet electoral el 65,2 por 100 de la población electoral; a este hecho contribuyó poderosamente el que tras la reforma del Código Electoral de enero de 1989 - menos de dos meses antes de las elecciones - el plazo para obtener el carnet electoral pasó de quince a treinta dias antes de las elecciones.

\section{La votación}

En los últimos comicios se establecieron 6.635 puntos electorales, aunque en 22 municipios no pudieron celebrarse las votaciones por ser zonas controladas por el FMLN. No obstante, mediante la reforma del Código Electoral de 25 de enero de 1989, los electores podian cambiar de lugar de votación mediante una solicitud, la ley no precisaba con qué antelación debían hacerse estas peticiones, lo que en la práctica significaba que aunque se favorecia que los ciudadanos tuvieran facilidades para ejercitar el derecho al voto, ello provocaba graves errores en el registro electoral y podia favorecer la utilización de un posible doble voto. 
El escrutinio de los votos se hace en las mesas inmediatamente acabada la jornada electoral y es de carácter público, celebrándose ante los representantes de los partidos políticos que concurren; posteriormente se levanta acta del resultado y se remite a la Junta Electoral Municipal, adjuntando los restantes documentos de la votación. La Junta Electoral Municipal, una vez llevado a cabo el escrutinio de las diversas actas, remite el resultado a la Junta Electoral Departamental, que a su vez lo remite al Consejo Central de Elecciones, que es el organismo encargado de proclamar los resultados.

El Consejo Central de Elecciones, según el Código Electoral, está compuesto por tres miembros elegidos por la Asamblea legislativa de las tres ternas presentadas por los tres partidos políticos mayoritarios; en todo caso, el presidente, según el artículo 11, será del partido mayoritario. Las Juntas electorales departamentales, municipales y de mesa están compuestas por cinco miembros (hasta la reforma de enero del 89 eran tres).

\section{El procedimiento electoral para la Presidencia y Vicepresidencia de la República}

Según el artículo 154, el período presidencial será de cinco años y terminará el día primero de junio, sin que la persona que haya ejercido la presidencia pueda continuar en sus funciones un dia más. Mediante el artículo 79, la fecha de elecciones para Presidente y Vicepresidente de la República deberá preceder no menos de dos meses antes ni más de cuatro a la iniciación del período presidencial.

El cumplimiento de estos preceptos constitucionales impidieron la aceptación del ofrecimiento del FMLN, que en conversaciones con el Gobierno solicitó quince dias antes de las elecciones su participación con sus propios candidatos en las mismas, solicitando el retraso de las elecciones en seis meses.

La campaña electoral (art. 81) comienza cuatro meses antes de la fecha establecida para las elecciones.

Las elecciones, según el artículo 80 , se establecen en un sistema a dos vueltas; si en la primera ningún candidato obtuviera mayoria absoluta, en la segunda vuelta sólo concurrirían los dos candidatos con mayor número de votos; esta segunda votación deberá celebrarse en un plazo no mayor de treinta días después de haberse declarado firmes los resultados de la primera vuelta. 


\section{FUERZAS POLITICAS CONCURRENTES}

- Acción Republicana Nacionalista (ARENA).-De ideología marcadamente derechista, muy ligado a los sectores más radicales del Ejército, partidario en primer lugar de ganar la guerra contra el FMLN. Fue fundado en septiembre de 1981. Su líder más representativo es Roberto D'Abvisson, que ya fue candidato a la Presidencia en 1984; presentaba como candidato oficial a Alfredo Cristiani para la Presidencia y a Francisco Merino para la Vicepresidencia. En su campaña propugnaba, junto a la línea dura ante la guerrilla y la corrupción administrativa, un modelo de economía liberal basada en la libre empresa y el fin de la intervención estatal en la economía.

- Partido Demócrata Cristiano (PDC).-De ideología democristiana, su figura más representativa era Napoleón Duarte, Presidente constitucional. Fue fundado en 1963, partidario de la negociación con el FMLN y de acometer reformas profundas en la estructura social del país, tales como la reforma agraria, asi como de intensificar la descentralización política y económica del país.

Era una candidatura de continuidad. Su candidato a la Presidencia era Fidel Chavez y Francisco Barrientos para la Vicepresidencia.

- Partido Coalición Nacional.-De ideología derechista y ligado a la dictadura anterior, fue fundado en 1961. Los candidatos a la Presidencia y Vicepresidencia eran Morán Castañeda y Dagoberto Marroquí, respectivamente.

- Acción Democrática.-Partido que intenta ser representativo de las clases medias, de ideología socialdemócrata, se alió con la Democracia Cristiana.

- El Movimiento Auténtico Cristiano.-Se trata de una escisión por la derecha del partido Demócrata Cristiano. Sus candidatos a la Presidencia y Vicepresidencia de la República eran Rey Prendes y Alex Salavarría.

- Partido Unión Popular (UP).--Ideología derechista moderadamente ligado a la burguesia industrial. De escasa implantación en el país, es fruto de la coalición del Partido Popular Salvadoreño y del Partido de Liberación. Su candidato a la Presidencia era Hugo Barrera.

- Partido Acción Renovadora (PAR).-De ideologia liberal, se opuso a la anterior dictadura. Presentaba como candidato a la Presidencia a Ernesto Oyárbide. 
- Convergencia Democrática (CD). - Ideología de centro izquierda, resultado de la unión del Movimiento Nacional Revolucionario, Movimiento Popular Socialcristiano y Democrático Social. Sus candidatos eran Guillermo Ungo y Mario Reni.

\section{RESULTADOS ELECTORALES}

- Posibles votantes:

- Inscritos:

1.800 .034

- Votos emitidos:

1.003 .153

- Votos válidos tot.:

939.078

- Votos nulos:

56.666

- Votos en blanco:

7.409

Ello significaba que se produjo una alta abstención, ya que del total de inscritos, 796.881, no acudió a las urnas, lo que representa el 44,2 por 100 , cifra que si la referimos al total de posibles votantes se aumenta a 1.509 .649 (60 por 100$)$.

\section{Desglose por fuerzas politicas}

\begin{tabular}{|c|c|c|}
\hline PARTIDOS POLITICOS & Votos & $\%$ \\
\hline - Alianza Republicana Nacionalista (ARENA) & 505.370 & 53,82 \\
\hline - Partido Demócrata Cristiano (PDC) & 338.369 & 36,03 \\
\hline - Partido Coalición Nacional (PCN) .... & 38.218 & 4,07 \\
\hline 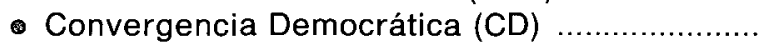 & 35.642 & 3,80 \\
\hline - Movimiento Auténtico Cristiano (MAC) ............. & 9.300 & 0,99 \\
\hline - Partido Unión Popular (UP) …................................ & 4.609 & 0,49 \\
\hline - Acción Democrática (AD) ... & 3.207 & 0,34 \\
\hline
\end{tabular}

Fuente: Boletín Electoral de CAPEL. M. ${ }^{a}$ Villaveces, 1989). 
Por tanto, a diferencia de anteriores comicios, no fue necesario recurrir a la segunda vuelta, ya que la Alianza Republicana Nacionalista (ARENA) obtuvo la mayoría absoluta de los votos emitidos en la primera vuelta.

\section{Conclusiones}

El resultado electoral, en el que destacan fundamentalmente el elevado indice de abstención, y especialmente las circunstancias en que se desarrollaron los comicios, plantea serias dudas sobre si de verdad está consolidado el sistema democrático. Empero, no deben ponerse en duda los esfuerzos del Gobierno Duarte para que la celebración de los comicios fuera lo más limpia posible, como así atestiguaron tanto la prensa internacional como los observadores oficiales de otros paises enviados por organismos internacionales.

La jornada electoral estuvo salpicada de incidentes que tuvieron una repercusión directa en la abstención, tales como la ofensiva guerrillera del FMLN, ausencia de transportes y carburantes en las gasolineras, etc. Ello significó el fracaso por parte del Gobierno democristiano de incorporar a la guerrilla al proceso de recomposición institucional del Estado, especialmente después de las últimas conversaciones habidas en Costa Rica.

\section{PANAMÁ}

\section{DATOS GENERALES}

La República de Panamá tiene una extensión de 75.650 km², excluida la zona del canal, bajo soberanía norteamericana hasta el año 2000 , y una población de 2.300 .000 habitantes, de los que 1.184 .320 componen el censo electoral panameño.

La incorporación efectiva a la Corona de Castilla del territorio que hoy constituye la República panameña fue en los inicios del siglo XVI, destacándose la creación de la Real Audiencia de Panamá en 1535. Durante el período colonial, no obstante su ubicación geográfica centroamericana, Panamá mantuvo una mayor dependencia de los territorios españoles de 
Sudamérica; así, salvo un corto período de dependencia de la Capitanía General de Guatemala, Panamá dependió del Virreinato de Perú y del de Santa $\mathrm{Fe}$, respectivamente. El acceso a la independencia del territorio se hizo conjuntamente con la Gran Colombia (1821) y desde 1841 formó parte de la República Colombiana, aunque desde 1851 gozaba de status federativo.

La creación, pues, de la República de Panamá es tardía en comparación con las restantes repúblicas iberoamericanas, datando de 1903, y puede considerarse consecuencia directa, no tanto de los deseos de un gran sector de los habitantes del territorio de Panamá de crear una República soberana independiente de Colombia, como de intereses foráneos partidarios de controlar el paso entre los dos océanos mediante la construcción del denominado canal de Panamá; afirmación ésta que se sostiene fundamentalmente en el hecho de que mediante el tratado Heran-Hay, primero y, Hay-Bunau Varilla (art. VII) y el propio texto constitucional de 1904 (art. 136), el ejército norteamericano establecido en el canal podía intervenir en caso de alteración del orden público en las ciudades de Panamá y Colón.

De esta forma, el acceso a la independencia de Panamá nace marcado por un doble aspecto derivado de la existencia del canal; así, por una parte, el país alberga en su seno a una de las mayores fuentes de riqueza del mundo, que no controla ni económica ni políticamente, y sobre la que no puede ejercer jurisdicción alguna, por la que percibe una renta anual fija que apenas significa porcentualmente algo en relación con los beneficios producidos por el tributo portuario; por otra parte, en esta franja de territorio relativamente extensa, $1.742 \mathrm{~km}^{2}$, en comparación con el territorio nacional, se encuentra una base del ejército más poderoso del mundo, de tal forma que no ha sido reconocida durante muchos años la soberanía de la República sobre la zona del canal.

Estos hechos a lo largo de la Historia han provocado situaciones dificiles de repetir en otros lugares del mundo. En primer lugar, cabe destacar la tutela norteamericana sobre la vida política y económica del país. Respecto a la tutela sobre la vida política panameña derivada de los artículos indicados anteriormente, es necesario indicar que la mayor parte de las veces no se ha producido a instancias del Gobierno norteamericano, ya que rara vez, exceptuados los últimos años, han peligrado los intereses norteamericanos en el país, tanto los del canal como los restantes de carácter agrícola, primero, y bancarios o comerciales, con posterioridad; por el contrario, la inestabilidad política de la República ha provocado que desde el acceso a la independencia, las fuerzas politicas panameñas, tanto liberales como conservadoras, hayan apelado a la intervención norteamericana: casos de 1912, 1916, 1920, 1924 y 1928, o bien hayan solicitado la supervisión de las elecciones al Gobierno norteamericano en 1908, 1912 y 1916; esta situación ha llevado a decir a algún constitucionalista que estamos ante un caso peculiar de soberanía tutelada, concepto ambiguo y 
eminentemente contradictorio pero que puede ayudarnos a comprender una compleja realidad política y constitucional.

Respecto a la situación económica derivada de los aspectos indicados anteriormente, cabe señalar que al amparo del canal y de la presencia norteamericana en el istmo desde 1903 hasta hace sólo unos años, numerosas empresas norteamericanas, primero, y transnacionales, después, se establecieron en el país, y fueron las grandes compañías agricolas entre las que cabe destacar la United Fruit Company norteamericanas, las que se establecen en las grandes zonas agrícolas del país alcanzando un gran desarrollo.

Posteriormente, las ciudades panameñas se convirtieron en sede de los más importantes bancos donde se desarrollaban los negocios provenientes, no sólo del gran flujo de dinero procedente del canal, sino también de las repúblicas vecinas de Sudamérica, que lo consideraban un refugio seguro; todo ello propició un desarrollo económico sólo comparable al existente en ciertos puertos de Extremo Oriente o de los propios Estados Unidos de Norteamérica.

De esta forma, en la medida en que la vieja oligarquía terrateniente y política panameña supo incorporarse a este proceso y convertirse en una burguesía comercial y financiera, se desarrollaron unas clases medias poderosas que hubieran debido ser la clave para la estabilización del sistema político.

Empero, la culminación de este proceso no tuvo exactamente estas consecuencias, ya que, en todo caso, el control de la economía o las directrices generales de la misma nunca pertenecían al poder político sino a un sistema mucho más internacionalizado; valga como ejemplo, el que aún hoy no exista una moneda nacional - ya que el balboa sólo afecta a la moneda fraccionaria-, siendo, por el contrario, el dólar estadounidense la moneda de uso.

\section{Los últimos años}

En 1968 el entonces coronel Omar Torrijos protagonizaría al frente de la Guardia Nacional un golpe de Estado que pondria fin al mandato presidencial de Arnulfo Arias Madrid. De esta forma el pais iniciaba un nuevo período que en muchos aspectos no ha terminado todavía.

El golpe de Estado se produce en un momento de cierto descrédito de las instituciones y clases políticas panameñas y de auge del nacionalismo, no ya sólo panameño, sino también latinoamericano. 
Omar Torrijos sabe jugar la baza nacionalista, motivado indudablemente en el caso panameño - al menos en las clases populares-, por la presencia en la zona del canal de soberania estadounidense, y consigue atraerse el apoyo de la burguesía local, fundamentalmente en su sector industrial, mediante una serie de reformas que posibilitaron la incorporación de la burguesía panameña al sistema económico internacional y no sólo de servicios en torno al canal. En suma, Torrijos, que es presentado por cierto sector internacional, en un principio, como revolucionario que puede poner en peligro la estabilidad política de la zona y de la economía mundial, se va a revelar como el estadista que transformará en cierta medida las estructuras sociales y políticas del país, mantendrá la estabilidad política en un período de diez años, resolverá en parte el contencioso exterior más importante mediante las negociaciones con Estados Unidos sobre la soberania del canal, y asegurará a las compañías transnacionales el desarrollo de su actividad en el canal. En el plano interno, en lo que afecta a las reformas estructurales acometidas en el país, podemos destacar las siguientes:

- Modernización del sistema productivo del país, creando una importante infraestructura mediante la intervención pública en ciertos sectores de la economía, lo que posibilitó el desarrollo de la burguesía industrial y financiera nacional que pudo incorporarse al sistema operativo de las transnacionales, dándoles los servicios que éstos requerian en un lugar como Panamá, y no sólo suministrando servicios al transporte del canal.

En este sentido se acometieron igualmente reformas en la agricultura desarrollando una reforma agraria; asimismo se acometieron reformas en la educación, sanidad, etc.

- En el aspecto constitucional se reformó la Constitución, en 1972, que fue redactada al efecto por una Asamblea Constituyente, reanudándose la vida politica parlamentaria, aunque con la presencia de las fuerzas armadas que juegan un papel muy importante en el proceso.

En política exterior negociará con la Administración Carter, alcanzando en 1978 un tratado que devolvía al pais en esas fechas algún territorio de la zona del canal y aseguraba la soberanía panameña sobre el resto del canal en 1999. A cambio, el Gobierno panameño iniciaba una apertura democrática que debería llevar al país a una vida parlamentaria plena no tutelada.

Posteriormente, en 1981, en accidente aéreo, y según algunos en extrañas circunstancias, moría Omar Torrijos. En todo caso, en ese mo- 
mento las circunstancias sociales y económicas en que estaba envuelto el pais eran muy diferentes a la de la toma del poder por Torrijos.

\section{EL MARCO SOCIAL Y ECONÓMICO}

Tras el auge económico de los últimos años de los sesenta y de la primera parte de la década de los setenta, el final de dicha década así como la siguiente tendrán un signo muy diferente: la crisis económica de mediados de los setenta derivada de la del petróleo de 1973 tendrá unas repercusiones en Panamá muy superiores a las de otros Estados de su misma renta per capita, y ello por varios motivos:

- Cualquier Estado soberano ante una situación de crisis económica internacional puede tomar medidas de carácter urgente que tiendan a proteger al menos su mercado interno y que eviten en lo posible su déficit comercial mediante el control de las importaciones. Sin embargo, una economía que está basada fundamentalmente en un concepto de apertura económica total y depende completamente de la estabilidad del mercado internacional es forzosamente mucho más vulnerable que cualquier otra que pueda ejercer un cierto control político, y las medidas que puede adoptar nunca afectarán al centro del problema, pues éste escapa totalmente de su control, no pudiendo ni siquiera aludir a una devaluación de su moneda que proteja sus exportaciones.

- Otros Estados con una economía aparentemente similar radicados en el sudeste asiático han podido superar estos aspectos negativos, pero el elemento diferenciador básico con Panamá ha sido que la zona geográfica en que está ubicada esta República, como consecuencia de la crisis, ha quedado virtualmente fuera de la división internacional del trabajo, con lo que el flujo de capitales a Panamá ha disminuido considerablemente, asi como el tránsito de mercancías por el canal.

Las consecuencias para la economía panameña han sido desastrosas: inflación, paro triplicado en diez años, etc. Las soluciones adoptadas: Congelación de salarios, endeudamiento exterior, etc.

De tal forma que el marco en que se desarrollan las elecciones de mayo de 1989 serán las de un país sujeto a una crisis económica no superada, endeudado, con alta inflación, paro, y en el que se ha exacerbado 
una política nacionalista que intenta explicar la situación, por otra parte agravada, por el enfrentamiento entre el hombre fuerte del país, el general Noriega, jefe de las fuerzas armadas desde 1983, y que desde 1985 mantiene una política de enfrentamiento con los Estados Unidos.

\section{EL SISTEMA ELECTORAL}

Mediante el Decreto núm. 44 de 7 de octubre de 1988, y en cumplimiento de lo dispuesto en el texto constitucional y el Código Electoral de 10 de agosto de 1983, modificado mediante la Ley núm. 9 de 21 de septiembre de 1988, el Tribunal Electoral convocó a elecciones para elegir Presidente y Vicepresidente (2) de la República, legisladores, concejales y representantes de los corregimientos.

\section{El cuerpo electoral}

Según el artículo 129 de la Constitución, el sufragio es de carácter obligatorio, libre, igual, universal, secreto y directo. No obstante, para poder ejercer el derecho al voto, según el Código Electoral de 10 de octubre de 1988, los ciudadanos deben obtener la cédula de identificación personal, que es facilitada por el Tribunal Electoral (art. 1), y estar inscritos en el Registro Electoral (art. 5).

Los electores emiten su voto según su residencia en una de las 4.255 mesas electorales sitas en 1.943 centros. Empero, por el artículo 7 del Código Electoral quedan exceptuados de votar en las mesas que les corresponde por residencia «los bomberos permanentes, los miembros de las fuerzas de defensa, los médicos, enfermeras y auxiliares" que estuvieran cumpliendo un turno que les imposibilitase votar en la mesa que les correspondiese, ejecutando su derecho al voto en la mesa más cercana al lugar en que estuviesen prestando servicio el día de las elecciones; a tal efecto el Tribunal Electoral los dotará de la correspondiente certificación.

Esta medida fue ampliamente combatida por la oposición política, que consideraba el apoyo en masa de los miembros de las fuerzas armadas a la candidatura de la Coalición de Liberación Nacional (COLINA), y que podia suponer que un colectivo de 20.000 electores pudiera votar en más de una ocasión; otra acusación de la oposición referente al censo era que éste había tenido un incremento espectacular desde 1984, de tal forma que 
en el informe llevado a cabo por la Alianza Democrática de Oposición Civilista (ADOC), el 3 de mayo de 1989 se evaluaba el aumento no explicado de votantes en 112.000 electores. En este sentido la oposición condicionó su participación a la derogación del Decreto 13 de 18 de abril de 1989 y los otros decretos que desarrollaban la Ley Electoral, aunque posteriormente decidió participar tanto en la campaña electoral como en los comicios.

Situándonos en un plano de estricto análisis del Registro Electoral, prescindiendo de otras valoraciones derivadas de la fortísima presión psicológica a que se vieron sometidos los electores durante todo el proceso electoral, tales como el nacionalismo exacerbado, presiones foráneas, rol de las fuerzas armadas, etc., aspectos que serán analizados posteriormente, podemos indicar que aun siendo muy difícil evaluar la distorsión del voto como consecuencia de que determinados funcionarios y profesionales pudieran votar en mesas diferentes a las que les correspondian, es necesario destacar que en el voto de funcionarios y militares no seria posible el doble voto si se aplicaba el artículo 7 del Código Electoral, así como el 9, ya que en éstos se establece que el Tribunal Electoral establecería los debidos controles, siendo necesario figurar en el Registro Electoral Final, correspondiendo al Tribunal Electoral hacer las confrontaciones necesarias para determinar si además votan en la mesa electoral en que originalmente debian hacerlo conforme al Registro Electoral, y de ser necesario, proceder a la imposición de la sanción penal electoral. Empero, el día de las elecciones numerosos votantes se presentaron a votar en mesas distintas a las que les correspondían provistos de la autorización pertinente, aunque en muchos casos, faltos del sello que las autentificaban; en estos casos correspondía a la mesa electoral correspondiente autorizar - no este acto. A este respecto, por parte de la oposición ADOC se produjeron numerosas quejas e impugnaciones. En todo caso, este procedimiento significaba una posible alteración importante, no ya en lo que respecta a la elección de Presidente y Vicepresidente de la República, como en cuanto a la elección de legisladores y, fundamentalmente, de representantes de los corregimientos y concejales, ya que en algunos casos podía suponer un incremento considerable en el colectivo de un municipio, de tal forma que electores que no residian en el mismo participaban en una votación para designar el poder municipal.

Respecto al Registro Electoral pudo comprobarse que, si bien era deficiente por la inexplicablemente mala informatización del mismo, distaba mucho de estar, como indicaba la oposición, sobrehinchado (22 por 100 de muertos, repeticiones, etc.), aunque si hubo muchos casos de los indicados; sin embargo, no es posible determinar con los datos que contamos, en qué porcentaje sufría alteraciones el mismo. 


\section{REPÚBLICA DE PANAMÁ}

\section{Tribunal Electoral}

(febrero-1989)

CANTIDAD DE ELECTORES, CENTROS Y MESAS DE VOTACIÓN POR PROVINCIA

\begin{tabular}{|c|c|c|c|}
\hline Provincias & $\begin{array}{l}\text { Cantidad de } \\
\text { electores } \\
\text { por provincia }\end{array}$ & $\begin{array}{c}\text { Cantidad de } \\
\text { centros }\end{array}$ & $\begin{array}{c}\text { Cantidad de } \\
\text { mesas }\end{array}$ \\
\hline BOCAS DEL TORO $\ldots \ldots \ldots \ldots \ldots \ldots \ldots \ldots$ & 31.170 & 75 & 123 \\
\hline COCLE $\ldots \ldots \ldots \ldots \ldots \ldots \ldots$ & 80.646 & 228 & 325 \\
\hline 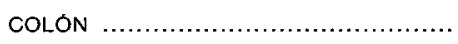 & 82.797 & 106 & 281 \\
\hline CHIRIQUJ $\ldots .$. & 172.712 & 374 & 649 \\
\hline DARIÉN & 12.499 & 46 & 61 \\
\hline HERRERA $\ldots \ldots \ldots \ldots \ldots$ & 54.437 & 175 & 249 \\
\hline 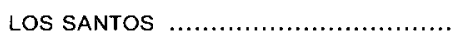 & 49.416 & 165 & 222 \\
\hline 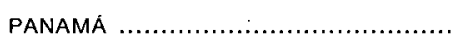 & 591.126 & 371 & 1.830 \\
\hline VERAGUAS .. & 93.878 & 358 & 452 \\
\hline SAN BLAS . & 15.639 & 45 & 63 \\
\hline TOTAL REPÚBLICA ... & 1.184 .320 & 1.943 & 4.255 \\
\hline
\end{tabular}


POSTULACIONES PARA LEGISLADORES, REPRES POR PARTIDO POLITICO Y PROVIN

\begin{tabular}{|c|c|c|c|c|c|c|c|c|c|c|c|c|c|c|c|c|c|c|}
\hline \multirow{2}{*}{$\begin{array}{l}\text { PARTIDOS } \\
\text { PROVINCIAS }\end{array}$} & \multicolumn{3}{|c|}{ LIBERAL } & \multicolumn{3}{|c|}{ PRD } & \multicolumn{3}{|c|}{ PDC } & \multicolumn{3}{|c|}{ MOLIRENA } & \multicolumn{3}{|c|}{ PALA } & \multicolumn{3}{|c|}{ REPUBLICAN } \\
\hline & L & $\mathbf{R}$ & $\mathrm{C}$ & L & $\mathbf{R}$ & $\mathrm{C}$ & $\mathrm{L}$ & $\mathbf{R}$ & c & L & R & $\mathrm{C}$ & L & R & c & L & $\mathbf{R}$ & \\
\hline BOCAS DEL TORO & 6 & 18 & - & 6 & 30 & 4 & - & 3 & 3 & 5 & 7 & 3 & 6 & 28 & 4 & 6 & 30 & \\
\hline COCLE ............. & 15 & 66 & 2 & 15 & 78 & 2 & 11 & 78 & 2 & 11 & 75 & 2 & 15 & 78 & 2 & 15 & 74 & \\
\hline COLÓN ....................... & 15 & 30 & - & 15 & 80 & - & 15 & 44 & - & 15 & 57 & - & 15 & 78 & - & 15 & 78 & \\
\hline CHIRIOUI & 28 & 93 & 8 & 30 & 198 & 8 & 33 & 145 & 8 & 33 & 135 & 4 & 33 & 193 & 8 & 24 & 173 & \\
\hline DARIÉN & 6 & 29 & 4 & 6 & 48 & 7 & - & - & - & 3 & - & - & 6 & 45 & - & 6 & 33 & \\
\hline HERRERA & 9 & 77 & 5 & 9 & 80 & 8 & 9 & 80 & 8 & 9 & 78 & 8 & 9 & 80 & 8 & 9 & 78 & 2 \\
\hline LOS SANTOS. & 9 & 128 & 2 & 9 & 144 & 2 & 9 & 124 & 2 & 9 & 124 & 2 & 9 & 142 & 2 & 9 & 122 & \\
\hline 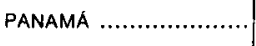 & 78 & 152 & - & 84 & 196 & 8 & 62 & 169 & 2 & 74 & 139 & 4 & 84 & 192 & 6 & 84 & 192 & \\
\hline VERAGUAS & 12 & 52 & - & 18 & 152 & 6 & 17 & 85 & 6 & 17 & 111 & 6 & 18 & 148 & 5 & 18 & 134 & \\
\hline SAN BLAS. & 6 & 6 & - & 6 & 8 & - & 6 & - & - & 6 & 1 & - & 6 & 8 & - & 6 & 8 & \\
\hline TOTALES & 184 & 651 & 21 & 198 & 1.014 & 45 & 162 & 728 & 31 & 182 & 727 & 29 & 201 & 992 & 35 & 192 & 922 & 6 \\
\hline
\end{tabular}

\footnotetext{
$\mathrm{L}=$ LEGISLADORES

$R=$ REPRESENTANTES

$\mathrm{C}=$ CONCEJALES
} 


\section{NTANTES DE CORREGIMIENTO Y CONCEJALES}

\section{A EN LA REPÚBLICA DE PANAMÁ}

\begin{tabular}{|c|c|c|c|c|c|c|c|c|c|c|c|c|c|c|c|c|c|c|}
\hline \multicolumn{3}{|c|}{$\begin{array}{l}\text { PNISTA. } \\
\text { AUTÉNTICO }\end{array}$} & \multicolumn{3}{|c|}{ PAN } & \multicolumn{3}{|c|}{ PDT } & \multicolumn{3}{|c|}{ PPR } & \multicolumn{3}{|c|}{$\begin{array}{c}\text { LIBERAL } \\
\text { AUT. }\end{array}$} & \multicolumn{3}{|c|}{ DEL PUEBLO } & \multirow{2}{*}{$\begin{array}{c}\text { TOTAL DE } \\
\text { POSTULACIONES } \\
\text { POR } \\
\text { PROVINCIA }\end{array}$} \\
\hline L & $R$ & c & L & $R$ & C & $\mathrm{L}$ & $\mathbf{R}$ & c & L & $\mathbf{R}$ & c & L & R & c & L & $R$ & C & \\
\hline 6 & 5 & - & 6 & - & - & 6 & 30 & - & 6 & 30 & 一 & 一 & - & - & 6 & 78 & 4 & 340 \\
\hline 10 & 28 & - & 13 & 18 & 2 & 6 & 72 & - & 14 & 40 & 2 & 11 & 78 & 2 & 15 & 48 & - & 900 \\
\hline 8 & 4 & - & 11 & - & - & 9 & 50 & - & 15 & 24 & - & 15 & 35 & - & 9 & 58 & - & 695 \\
\hline 22 & 14 & 2 & 21 & 16 & 8 & 27 & 36 & 2 & 15 & 120 & 6 & 33 & 155 & 8 & 4 & 70 & 2 & 1.715 \\
\hline 4 & - & - & 6 & 22 & - & 6 & 48 & - & 6 & 28 & - & 3 & - & - & 6 & 26 & - & 348 \\
\hline 3 & 6 & - & 9 & 80 & 8 & 3 & 80 & - & 9 & 75 & 4 & 9 & 80 & 8 & 9 & 80 & 8 & 1.037 \\
\hline 6 & - & - & 9 & 72 & - & 6 & 110 & - & 9 & 102 & - & 9 & 122 & 2 & 9 & 106 & 2 & 1.412 \\
\hline 53 & 62 & - & 57 & 126 & - & 44 & 160 & - & 66 & 152 & 8 & 81 & 150 & - & 66 & 196 & - & 2.747 \\
\hline 4 & 4 & - & 18 & 41 & - & 18 & 6 & - & 15 & 146 & 6 & 15 & 84 & 6 & 15 & 148 & 6 & 1.337 \\
\hline - & - & - & 6 & - & - & 6 & 一 & - & 6 & - & - & - & - & - & 6 & 6 & - & 97 \\
\hline 16 & 123 & 2 & 156 & 375 & 18 & 131 & 592 & 2 & 161 & 717 & 26 & 176 & 704 & 26 & 145 & 816 & 22 & \\
\hline
\end{tabular}




\section{CALENDARIO ELECTORAL}

7 de octubre de 1988: Convocatoria a elecciones.

7 de noviembre de 1988: Apertura del proceso electoral.

7 de noviembre de 1988: Publicación y entrega del Registro Electoral Actualizado Preliminar.

7 de noviembre de 1988 al 7 de febrero de 1989: Presentación de postulaciones por partidos políticos.

7 de noviembre al 7 de diciembre de 1988: Presentación de candidaturas por libre postulación (concejales y representantes).

7 de noviembre de 1988 al 7 de enero de 1989: Inscripción de adherentes de candidaturas por libre postulación.

8 de noviembre al 8 de diciembre de 1988: Presentación de impugnaciones del Registro Electoral Actualizado Preliminar.

8 de noviembre al 22 de diciembre de 1988: Presentación de omisiones al Registro Electoral Actualizado Preliminar.

8 de noviembre de 1988 al 12 de enero de 1989: Período para presentar impugnaciones de adherentes de candidaturas por libre postulación.

22 de diciembre de 1988: Fecha final para solicitud de cédula de los menores que llegan a la mayoría de edad entre el 7 de noviembre de 1988 y el 6 de mayo de 1989.

22 de diciembre de 1988: Cierre del periodo para trámites de inclusión o cambios de residencia en el Registro Electoral Actualizado Final.

15 de enero de 1989: Publicación de la lista de personas que formalizaron oportunamente cambios de residencia o solicitaron su inclusión al Registro Electoral.

16 al 30 de enero de 1989: Periodo de impugnar los cambios de residencia o la inclusión de las personas a que se refiere la lista anterior. 
6 de febrero de 1989: Cierre de recibo de solicitud de cédula.

7 de febrero de 1989: Publicación y entrega del Registro Electoral Actualizado Final.

7 de febrero de 1989: Última fecha en que los servidores públicos que aspiran a cargos de elección popular deben separarse.

8 al 22 de febrero de 1989: Período de impugnar cambios de residencia o inclusiones en el Registro Electoral Actualizado Final y para corregir omisiones en el mismo.

6 de marzo de 1989: Cierre de solicitudes de duplicado de cédula.

7 de marzo de 1989: Sorteo de los colores de las boletas de los candidatos por libre postulación.

6 de abril de 1989: Término para que los partidos políticos envíen al Tribunal Electoral el listado de sus representantes en las mesas, centros de votación y las Juntas de Escrutinio.

6 de abril de 1989: Término para que las personas contempladas en los artículos 7 y 8 del Código Electoral soliciten su inclusión en la lista adicional señalada en el artículo 9 del Código Electoral

7 de abril de 1989: Cierre de expedición de cédula.

7 de abril de 1989: Notificación a los partidos y a los candidatos independientes de la ubicación de las mesas de votación.

6 de mayo de 1989: Último día para la entrega de cédula de indentidad personal a las personas que alcanzaron su mayoría de edad antes de las elecciones y cumplieron con lo establecido en el artículo 20 del Código Electoral.

7 de mayo de 1989: Celebración de las elecciones para Presidente y Vicepresidentes de la República, para legisladores, concejales y representantes de Corregimientos.

\section{El procedimiento electoral}

La Constitución panameña en su artículo 136 establece que es el Tribunal Electoral, de carácter autónomo, el que interpretará y aplicará la Ley Electoral, dirigiendo, vigilando y formalizando la misma. 
El Tribunal está compuesto por tres magistrados designados por diez años entre aquellos que reúnan los mismos requisitos para ser miembros de la Corte Suprema de Justicia, siendo responsables ante ésta por las faltas o delitos cometidos en el ejercicio de sus funciones. Los tres magistrados son designados por el Órgano Legislativo, Ejecutivo y la Corte Suprema, respectivamente. En el momento de la elección, el Tribunal estaba compuesto por Yolanda Pulice en la presidencia, Luis Carlos Chen en la vicepresidencia y Raúl A. López como magistrado vocal.

El resto de las corporaciones locales son según el artículo 2 del Decreto núm. 2 de 26 de enero de 1989: la Junta Nacional de Escrutinio, con jurisdicción en toda la República; las Juntas de Escrutinio de Circuitos electorales, con jurisdicción en los respectivos circuitos; las Juntas Distritoriales de Escrutinio, con jurisdicción en todos los distritos en donde exista elección para concejales; las Juntas Comarcales de Escrutinio, con jurisdicción en los respectivos Corregimientos, y las mesas de votación, con jurisdicción en las mesas respectivas.

Las mesas de votación, que están compuestas (art. 157 del Código Electoral) por un presidente, secretario y vocal designado por el Tribunal Electoral, más un representante por cada partido o candidato, una vez realizada la votación procede a realizar el recuento de votos y levantar las actas correspondientes que se remitirán (por la Presidencia y Vicepresidencia) a la Junta Nacional, Tribunal Electoral y Junta de Escrutinio del Circuito (legisladores), a la Junta de Circuito y al Tribunal Electoral (concejales), a la Junta Distritorial, a la Junta Comunal y al Tribunal Electoral. Posteriormente son destruidas las papeletas sobrantes y quemados los votos.

Las Juntas Comunales de Escrutinio, con sede en el Corregimiento correspondiente, compuesta según los mismos criterios que las mesas de votación (art. 152 del Código Electoral), en sesión pública procede a recontar las actas de los diferentes procesos de votación y a escrutar los resultados del Corregimiento, posteriormente procede a proclamar a los candidatos que hayan obtenido la mayoria de los votos, remitiendo al Tribunal Electoral un ejemplar original del acta del escrutinio y de proclamación.

Las Juntas Distritoriales de Escrutinio, con sede en la cabecera del distrito, integradas de igual forma que las anteriores, tienen como función el recuento de las diversas actas recibidas, así como la proclamación de concejales, remitiendo el acta correspondiente al Tribunal Electoral.

Las Juntas de Escrutinio de Circuitos Electorales, de composición idéntica a las anteriores, procederá al escrutinio de las elecciones para Presidente, Vicepresidente y legisladores, remitiendo acta de las primeras a la Junta Nacional, que deberá ser llevada por el secretario del Tribunal, y remitiendo copia al Tribunal Electoral; igualmente procederá, según el 
artículo 275 del Código Electoral, a proclamar a los candidatos para legisladores que hubieran sido elegidos.

La Junta Nacional de Escrutinio, con sede en la capital de la República, compuesta según criterio indicado para las otras corporaciones, una vez recogidas las actas de escrutinio provenientes de las Juntas de Escrutinio de los Circuitos Electorales y de las mesas de votación y verificados los resultados de dichas actas, proclamará como Presidente y Vicepresidentes de la República a los candidatos que hayan obtenido la mayoría de votos, de conformidad con los cómputos realizados sin perjuicio de los recursos de nulidad de las elecciones o de las proclamaciones.

El dia de las elecciones estuvo salpicado de incidentes, especialmente una vez cerrados los comicios; fueron numerosas las denuncias presentadas por la oposición ADOC, ya que ésta sostenía que numerosos votantes lo habian hecho en más de una ocasión mediante la oportuna falsificación del permiso del Tribunal Electoral para votar fuera de su circunscripción; no obstante, los incidentes fueron creciendo durante la noche del 7 al 8 de mayo y especialmente al día siguiente. El motivo fundamental era el inexplicable retraso en llegar los resultados electorales a la Junta Electoral, así como la acusación de la oposición de que se estaba procediendo a un falseamiento de los datos mediante una nueva confección de actas. En todo caso, un hecho que pudo ser comprobado por los observadores oficiales y del Parlamento europeo fue que algunas de las Juntas de Escrutinio de los Circuitos Electorales cuando se estaba procediendo al recuento de actas fueron asaltadas en la noche del 7 al 8 de mayo por grupos incontrolados que llegaron a destruir toda la documentación existente allí.

\section{Clima electoral}

En el clima de tensión que vivió el país durante el proceso electoral degeneró tras la celebración de las elecciones en auténtico ambiente de violencia, de tal forma que el día 8 de mayo, en el transcurso de una manifestación de la oposición, se produjeron los primeros incidentes armados iniciados por grupos incontrolados que atacaron a los componentes de la misma, lo que se repitió en días posteriores llegando a herir a varios de los principales candidatos de la oposición.

El hecho de que no se dieran a conocer los resultados por las Juntas Electorales y que sólo parcialmente por fuentes oficiales se diera una primera información el día 9 sobre un pequeño número de votos que daban como ganadores a la coalición oficial (COLINA) propició el incremento de los enfrentamientos entre partidarios de las diversas fuerzas políticas y el nacimiento de rumores de todo tipo, entre los que destacaba la posibilidad 
de una intervención militar norteamericana, lo que exacerbó los ánimos nacionalistas hasta extremos muy considerables.

En este contexto, el Tribunal Electoral el día 10 de mayo, en aplicación del artículo 290 del Código Electoral, procedía a declarar la nulidad de las elecciones.

\section{FUERZAS POLITICAS CONCURRENTES}

Doce fueron las fuerzas políticas concurrentes a las elecciones de mayo de 1989 (LIBERAL, PRD, PDC, MOLIRENA, PALA, I. REPUBLICANA, PANAMEÑISTAS AUTENTICOS y P. DEL PUEBLO [véase cuadro adjunto] )

Empero, estas fuerzas políticas pueden agruparse en tres grandes bloques que postulaban cada uno por un único Presidente y dos Vicepresidentes.

\section{Estas fuerzas eran las siguientes:}

- Coalición de Liberación Nacional (COLINA).-Era considerada como la candidatura oficial. Estaba compuesta por los siguientes partidos: Partido Revolucionario Democrático, Partido Laborista, Partido Panameñista Revolucionario, Partido Republicano, Partido Republicano de los Trabajadores, Partido del Pueblo y Partido de Acción Nacional. Según cifras oficiales suministradas a la Secretaría de Proceso e Información del Tribunal Electoral por la Dirección de Estadística, para el 10 de marzo esta coalición contaba con 441.972 miembros, de los cuales 200.482 lo eran del PRD, lo que le convertía en la fuerza política más numerosa de la coalición y del pais. Posteriormente, el Tribunal Electoral el 28 de abril de 1989, según información del periódico La República Dominical del 7 de mayo, daría cuenta de un importante incremento de militantes de esta coalición, quedando asi:

- PRD

- PAla 
- P. Republicano

- PAN

- PDT

- PPP

- PPR

El candidato presentado por esta coalición a la Jefatura del Estado era Carlos Alberto Duque Jaén; sus candidatos a las Vicepresidencias eran Ramón Sieiro Murgas (1. ${ }^{a}$ Vicepresidencia) y Aquilino Edgar Boyd de la Guardia (2. ${ }^{a}$ Vicepresidencia).

- Alianza Democrática de Oposición Civilista (ADOC) que según las fuentes indicadas anteriormente contaba en marzo del 89 con 83.041 militantes, de los que 39.553 pertenecian al partido mayoritario de la alianza MOLIRENA. Posteriormente, La República Dominical del 7 de mayo del 89, publicaba los siguientes datos:

- MOLIRENA

- PDO. DEMÓCRATA CRISTIANO

- PDO. LIBERAL AUTÉNTICO

ADOC estaba formado por los siguientes partidos políticos: Partido Liberal Auténtico, Partido Demócrata Cristiano, Partido Movimiento Liberal Republicano Nacionalista (MOLIRENA).

Su candidato a la Presidencia era Guillermo Endara Galimany, y a la Vicepresidencia, primero y segundo, respectivamente, Ricardo Arias Calderón y Guillermo (Billy) Ford Boyd. 
- Partido Panameñista Auténtico (Arnulfistas).-Sus candidatos eran Hildewando A. Nicosia Pérez para la Presidencia y Alfonso Manuel Díaz Tablate (Vicepresidencia primera) y Emiliano Ponce Arce (Vicepresidencia segunda). Este partido, según las citadas fuentes, contaba con 32.293 militantes, aunque el diario citado anteriomente le daba el 7 de mayo un total de 41.159 miembros.

\section{RESULTADOS ELECTORALES}

La anulación de las elecciones por el Tribunal Electoral y los graves hechos ocurridos imposibilitaron el conocimiento, no ya de los resultados totales, sino que incluso obligó a rechazar algunos parciales habidos. Cabe destacar, sin embargo, que la Junta Electoral, cuarenta horas después del cierre de las urnas, dio a conocer algunos resultados referentes a cuatro cricuitos que representaban el 4 por 100 del censo y que daban la victoria a la coalición COLINA por dos a uno con respecto a ADOC (32.282 votos frente 16.496). Estos resultados no fueron aceptados por las demás fuerzas políticas concurrentes, de tal forma que se autoproclamaron vencedores los partidos integrados en ADOC.

Por su parte, la Conferencia Episcopal realizó un sondeo amplio cuyos resultados daban como vencedora a la coalición ADOC (con las tres cuartas partes del electorado frente un cuarto del mismo para COLINA). Por otra parte, la opinión de la mayoría de los observadores internacionales que habian estado en diversas mesas hasta el recuento final era que había ganado la oposición ADO-CIVILISTA, con el 65 por 100 aproximadamente, frente COLINA, que habría obtenido un 25 por 100, y el Partido Panameñista Auténtico, que no habría pasado del 4 por 100; no obstante, es de resaltar que los observadores consultados por el autor de este informe no se habian desplazado más allá de $100 \mathrm{~km}$. de la capital panameña, y dentro de este ámbito, las mesas estudiadas habrian sido forzosamente escasas.

Respecto a encuestas publicadas con anterioridad a la celebración de las elecciones la tónica era la misma, las de instituciones más ligadas a sectores oficiales daban mayoría a la coalición COLINA (dos a uno), mientras que las otras otorgaban una amplia mayoria a ADOC: entre estas últimas cabe destacar la llevada a cabo por el Departamento de Noticias Univisión, con Bendixen-Schroth, que suele hacerlas desde 1984 para América Latina, con un margen de error comprobado no superior al 4 por 100 y teórico medio de $\pm 2,7$ por 100 , a excepción de lo que sucedió en las elecciones mexicanas, cuyo margen de error fue del 10 por 100. 
En la encuesta de las elecciones panameñas se otorgaba al candidato presidencial Guillermo Endara el 61 por 100, frente a Carlos Duque, 27 por 100, y al candidato Nicosia Pérez, sólo un 3 por 100 . La encuesta fue hecha del 11 al 18 de abril sobre una muestra de 1.312 votantes.

\section{Conclusiones}

El proceso y desenlace electorales han puesto de manifiesto que la República de Panamá está todavía lejos de consolidar su transición hacia un Estado democrático, aunque ello no quiere decir que no sea deseado por la gran mayoría del pueblo.

Son demasiados todavia los factores y presiones que están imposibilitando este desenlace; entre ellos destacarian los siguientes:

- Crisis económica: El vertiginoso aumento del paro y la inflación cuya solución es incontrolable por las autoridades políticas y económicas del pais, en virtud de la profunda dependencia exterior en este aspecto.

- Presiones foráneas: El control de la zona del canal y la histórica dependencia que el país ha tenido de los Estados Unidos de Norteamérica, implica que indudablemente el punto de vista norteamericano ante el conflicto haya de ser tenido en cuenta en cualquier salida que forzosamente habrá de ser negociada en el interior entre todas las fuerzas y grupos de presión existentes, y en el exterior con los Estados Unidos. Otra alternativa no podrá ser duradera.

- Exacerbado nacionalismo: El país o gran parte de la población ha sido movilizado por determinadas fuerzas políticas y sociales, desarrollando un exacerbado nacionalismo que si bien se ha puesto en marcha es muy difícil que pueda pararse si no se produce alguna compensación clara, tal como que el canal revierta a la República panameña, de tal forma que las actitudes ideológicas impiden en muchos casos soluciones por medio de acuerdos que reconduzcan a una salida negociada entre las dos partes en que se encuentra dividido el pais y que hoy por hoy son irreconciliables, mucho más que cuando se inició el proceso electoral.

- Por otra parte, el rol que tienen las fuerzas armadas debido a la pérdida de prestigio de otras instituciones estatales hace que en cualquier salida negociada éstas han de estar presentes. 
- Otro claro factor de desequilibrio es la conflictiva situación de Centroamérica en la que, exceptuada Costa Rica y acaso Honduras y Guatemala, se haya dividida en opciones políticas irreconciliables que sólo ven la solución de sus problemas en el triunfo absoluto sobre el otro bando, de tal forma que no se acepta sino como imposición externa, la validez del sistema democrático como medio para resolver problemas. En este contexto puede ser tentador para algunos sectores panameños alinearse con determinados países para justificar una salida no democrática. Con posterioridad a los comicios se produjo la invasión norteamericana, que tras destituir al general Noriega y deshacer el poder político panameño posibilitó que Guillermo Endara asumiera la Jefatura del Estado, sin que hasta el momento la nación haya sido convocada nuevamente ante las urnas.

Es por todo ello por lo que en contra de lo que piden algunos, tanto dentro del país como fuera de él, es necesario en nuestra opinión que antes de acudir a nuevos comicios debe negociarse entre todas las partes implicadas, tanto internas como externas, una salida que posibilite que el próximo resultado electoral, sea el que sea, sea aceptado por todas las partes y no suponga alteraciones del desarrollo económico y social del país. En caso contrario, un nuevo proceso electoral fracasado supondría la pérdida de la fe en este tipo de sistema político y un paso atrás en la historia de la República. 